\title{
RORA Polymorphism Interacts with Childhood Maltreatment in Determining Anxiety Sensitivity by Sex: A Preliminary Study in Healthy Young Adults
}

\author{
Jung-Ah Min ${ }^{1}$, Heon-Jeong Lee ${ }^{2}$, Seung-Hwan Lee ${ }^{3}$, Young-Min Park ${ }^{3}$, Seung-Gul Kang ${ }^{4}$, Young-Gyu Park ${ }^{5}$, \\ Jeong-Ho Chae ${ }^{6}$ \\ ${ }^{1}$ Department of Psychiatry, Incheon St. Mary's Hospital, College of Medicine, The Catholic University of Korea, Incheon, ${ }^{2}$ Department of Psychiatry \\ and Division of Brain Korea 21 Biomedical Science, Korea University College of Medicine, Seoul, ${ }^{3}$ Department of Psychiatry, Inje University \\ College of Medicine, Ilsan, ${ }^{4}$ Department of Psychiatry, Gachon University School of Medicine, Incheon, ${ }^{5}$ Department of Biostatistics, College \\ of Medicine, The Catholic University of Korea, Seoul, ${ }^{6}$ Department of Psychiatry, Seoul St. Mary's Hospital, College of Medicine, The Catholic \\ University of Korea, Seoul, Korea
}

\begin{abstract}
Objective: Recent studies have reported associations of retinoid-related orphan receptor alpha (RORA) gene single nucleotide polymorphisms (SNPS) with depression and anxiety disorders. Based on these, we attempt to test whether RORA polymorphism is associated with anxiety sensitivity (AS), the intermediate phenotype of depression and anxiety disorders. Considering gene-environment interactions and sex differences in AS, childhood maltreatment (CM) and sex were considered as confounders.

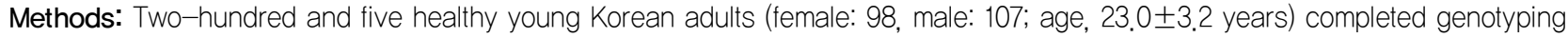
for the RORA SNP rs11071547, as well as measures for AS and CM. Generalized linear models were used to examine the main and interaction effects of RORA genotype, CM, and sex in determining AS.

Results: The main effect of RORA polymorphisms was not found $(p=0.760)$ whereas the main effect of $\mathrm{CM}$ and interaction effects among sex, genotype, and maltreatment were significant on AS. In separate analyses by sex, the interaction effect between RORA genotype and maltreatment was significant only in males $(p<0.001)$. In females, the main effects of genotype and $\mathrm{CM}$ were significant (both were $p<0.001$ ), in which both a history of $\mathrm{CM}$ and $\mathrm{C}$ genotype tended to be associated with higher AS. Conclusion: The association between RORA polymorphism and AS might differ by sex. The interaction between RORA polymorphism and CM was significant only in males whereas RORA genotype and CM independently associated with AS in females. Further studies are encouraged to confirm the relationship between RORA polymorphism and AS.
\end{abstract}

KEY WORDS: Gene-environment interaction; Retinoid acid receptor-related orphan receptor alpha (RORA) gene; Childhood trauma; Sex; Anxiety sensitivity.

\section{INTRODUCTION}

It has been suggested that retinoid-related orphan receptor alpha (RORA) gene single nucleotide polymorphisms (SNPs) pose a risk for depression ${ }^{1-3)}$ and fear-related internalizing psychopathologies including panic, phobia, and obsessive-compulsive disorders. ${ }^{4}$ Recent reports have also demonstrated that RORA polymorphisms might be associated with posttraumatic stress disorder after exposure to various types of lifetime trau-

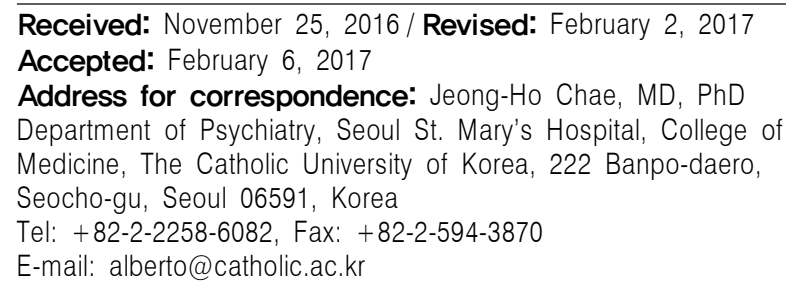

$\mathrm{ma}^{5)}$ and a hurricane. ${ }^{6}$ These results put questions whether RORA polymorphism is associated with an intermediate phenotype of depression and anxiety disorders, as well as how it interacts with traumatic experiences.

Anxiety sensitivity (AS) has been proposed as the potential intermediate phenotype of depression and anxiety disorders. ${ }^{7,8)}$ The individual levels of AS are thought to be influenced by genetic and environmental factors, such as childhood maltreatment (CM) ${ }^{9,10)}$ Regarding genetic factors, the polymorphisms of serotonin transporter gene ${ }^{7,11)}$ and neuropeptide $\mathrm{S}$ receptor gene ${ }^{12)}$ have been reported to interact with $\mathrm{CM}$ in determining AS.

We aimed to test whether the RORA genotype is associated with AS among healthy young adults. Considering the proposed sex differences in $\mathrm{AS}^{13)}$ as well as the geneenvironment interaction in determining $\mathrm{AS},{ }^{14,15)} \mathrm{CM}$ and sex were regarded as possible confounders.

(a) This is an Open-Access article distributed under the terms of the Creative Commons Attribution Non-Commercial License (http://creativecommons.org/licenses/by-nc/4.0) which permits unrestricted non-commercial use, distribution, and reproduction in any medium, provided the original work is properly cited. 


\section{METHODS}

\section{Participants}

Healthy young adults were recruited by newspaper advertisement in Seoul, Republic of Korea. Participants were confirmed to be free from lifetime or current diagnosis of any psychiatric disorders and neurologic diseases through an interview with an experienced psychiatrist using the Structured Clinical Interview for the Diagnostic and Statistical Manual of Mental Disorders, fourth edition (SCID I and II). Among the 205 unrelated Koreans completed study procedures, 107 (52.2\%) were male and a mean age was 23.0 (standard deviation [SD], 3.2; range, 18-31) years. All participants provided written informed consent prior to participation. The study protocol was approved by the Institutional Review Board at Seoul St. Mary's Hospital, The Catholic University of Korea (KC10TIMI0434).

\section{Measures}

Individual AS was measured by Anxiety Sensitivity Index-Revised (ASI-R). ${ }^{16,17)}$ It is rated on a 5-point Likert scale from 0 to 4 . Higher total score means higher AS.

The short form of the Childhood Trauma Questionnaire (CTQ) was used to evaluate a history of $\mathrm{CM}^{18,19)}$ The CTQ is a self-report questionnaire consisting of 28 items that measure five categories of CM including emotional and physical neglect as well as emotional, physical, and sexual abuse. Each category consists of five items rated on a 5-point Likert scale. Based on the manual specifying cutoff points for the levels of none, low, moderate, and severe ${ }^{20)}$ the moderate to severe cutoff scores for each subscale were used to determine positive in that category and having one or more positive categories was regarded as the presence of $\mathrm{CM}^{21,22)}$

\section{Genotyping}

The RORA rs11071547 was selected based on the previous study that reported its association with sleep disorder as one of the circadian clock genes. ${ }^{23)}$ The rs 11071547 is located in the intron region of RORA gene on chromosome 15 . Blood samples $(5-10 \mathrm{ml})$ were collected into an ethylenediaminetetraacetic acid (EDTA) tube, and genomic DNA was isolated using a NucleoSpin ${ }^{\circledR}$ Blood DNA Extraction Kit (Macherey-Nagel, Düren, Germany) according to procedures from the manufacturer's manual. Genotyping was performed by high-resolution melting curve analysis. Polymerase chain reaction (PCR) was performed in a volume of $20 \mu \mathrm{l}$ per reaction with a 96-well Bio-Rad CFX96 Real Time PCR system (Bio-Rad, Hercules, CA, USA). Reaction mixtures included $1.5 \mu \mathrm{l}$ of genomic DNA as a template and each primer for the rs11071547 SNP of RORA at $200 \mathrm{mM}$ (forward 5'-TGC CTA CCG CTT TCC TTT-3', and reverse 5'-AAA TAA ACT TGG AGT GTT CTG GA-3'), 1×Sso Fast EvaGreen SuperMix (Bio-Rad) and sterile $\mathrm{H}_{2} \mathrm{O}$. The amplification protocol started with $98^{\circ} \mathrm{C} / 3$ minutes followed by $39 \mathrm{cy}-$ cles of $98^{\circ} \mathrm{C} / 10$ seconds and $58^{\circ} \mathrm{C} / 20$ seconds. After an initial step of $95^{\circ} \mathrm{C} / 10$ seconds and $65^{\circ} \mathrm{C} / 10$ seconds, melting curves were generated from $65^{\circ} \mathrm{C}$ to $95^{\circ} \mathrm{C}$ in increments of $0.3^{\circ} \mathrm{C} /$ cycle. Melting profiles were analyzed with Bio-Rad Precision Melt software.

\section{Statistics}

The Hardy-Weinberg equilibrium for genotype distribution was tested by the $\chi^{2}$ test. Between-group comparisons were performed with independent $t$-test or one-way analysis of variance and $\chi^{2}$ test for continuous and categorical variables, respectively. The relationship between continuous variables was examined by Pearson's correlation analysis. Generalized linear models were used to explore the main effects of sex, RORA genotype, and $\mathrm{CM}$ with all possible two- and three-way interaction effects on AS. Data were analyzed with SAS software ver. 9.0 (SAS Institute, Inc., Cary, NC, USA). All statistical tests were two-tailed, and $\alpha$ was set at 0.05 .

\section{RESULTS}

Distributions of the alleles and genotypes of RORA rs 11071547 were in Hardy-Weinberg equilibrium $\left(\chi^{2}=0.480\right.$, $p=0.488$ ). Among 205 participants, the allelic frequencies of $\mathrm{C}$ and $\mathrm{T}$ were $36.1 \%(\mathrm{n}=148)$ and $63.9 \%(\mathrm{n}=262)$, respectively. These frequencies are similar to reported distributions among general populations of China and Japan in the HapMap database (http://www.hapmap.org). The genotype frequencies of $\mathrm{C} / \mathrm{C}, \mathrm{C} / \mathrm{T}$, and $\mathrm{T} / \mathrm{T}$ were $14.1 \%$ $(\mathrm{n}=29), 43.9 \%(\mathrm{n}=90)$, and $42.0 \%(\mathrm{n}=86)$, respectively. We reclassified the three genotypes into two groups, $\mathrm{C}$ $(\mathrm{C} / \mathrm{C}$ and $\mathrm{C} / \mathrm{T}, \mathrm{n}=119)$ and $\mathrm{T} / \mathrm{T}(\mathrm{n}=86)$.

Mean scores of AS was $20.8(\mathrm{SD}=14.8)$. One or more types of CM were reported among 87 (42.4\%) participants, in which 32, 30, 11, 54, and 24 individuals reported a history of emotional neglect, physical neglect, emotional abuse, physical abuse, and sexual abuse, respectively. Participants with $\mathrm{CM}$ showed significantly higher AS than those without $(p=0.015)$. The frequencies of RORA genotype and sex as well as the mean ages did not 

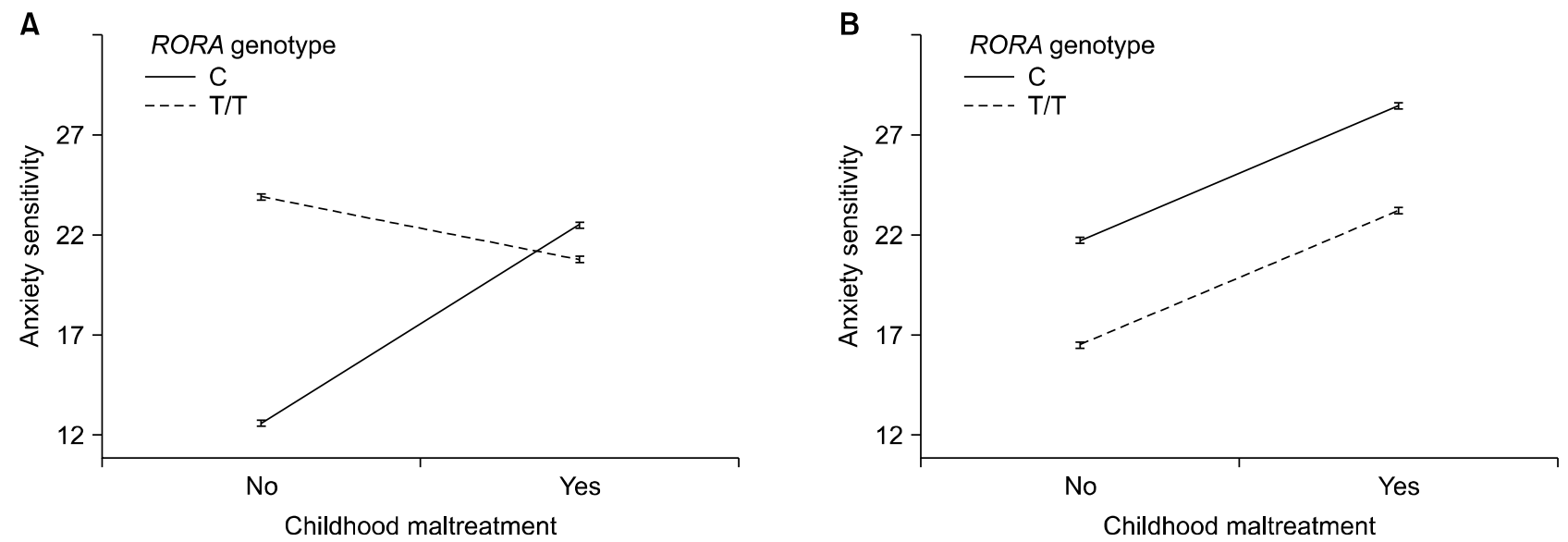

Fig. 1. Interaction effects between RORA polymorphism and childhood maltreatment on anxiety sensitivity by sex. The interaction effect was significant in male subects (A), whereas main effects of RORA genotype and childhood maltreatment were significant in female subjects (B).

Table 1. Results of generalized linear model examining the effect of sex, childhood maltreatment, and RORA genotype on anxiety sensitivity (WALD type 3 statistic)

\begin{tabular}{|c|c|c|c|}
\hline Source & df & $\chi^{2}$ test & $p$ value \\
\hline Age & 1 & 83.02 & $<0.001$ \\
\hline Sex & 1 & 13.36 & $<0.001$ \\
\hline Genotype (RORA polymorphism) & 1 & 0.09 & 0.760 \\
\hline Maltreatment & 1 & 58.13 & $<0.001$ \\
\hline Sex×genotype & 1 & 59.46 & $<0.001$ \\
\hline Sex $\times$ maltreatment & 1 & 2.61 & 0.106 \\
\hline Genotype×maltreatment & 1 & 20.49 & $<0.001$ \\
\hline Sex×genotypexmaltreatment & 1 & 34.43 & $<0.001$ \\
\hline
\end{tabular}

Omnibus test $(p<0.001)$.

df, degree of freedom.

differ significantly by a history of CM ( $p=0.668,0.114$, 0.791 , respectively). Age showed significant negative association with AS $(\mathrm{r}=-0.178, p=0.010)$.

In the generalized linear model controlling for age (Table 1), the main effect of RORA genotype was not significant whereas that of CM was significant in predicting AS. There were significant three-way interaction among sex, genotype, and CM. In separate models by sex (Fig. 1), the interaction effect between genotype and CM was significant only in males $\left(\chi^{2}=64.70, p<0.001\right)$. The T/T genotype was associated with the higher AS than $\mathrm{C}$ genotype among males without $\mathrm{CM}(p=0.016)$, whereas there was no difference in AS by genotype among males with CM $(p=0.565)$. In females, the main effects of genotype and CM were significant $\left(\chi^{2}=19.73, p<0.001\right.$ and $\chi^{2}=27.25, p<$ 0.001 , respectively), in which the history of CM and C genotype were associated with higher AS.

\section{DISCUSSION}

This preliminary study did not found the association between RORA rs11071547 genotype and AS. However, we demonstrated the sex-specific interactions between RORA genotype and $\mathrm{CM}$ in determining AS. The RORA genotype interacted with $\mathrm{CM}$ in males, whereas each of $R O R A$ genotype and CM were significant predictor of AS in females. These results suggest the possible role of sex in interaction between RORA polymorphism and CM to determine AS.

RORA protein plays a role in maintaining circadian rhythm. ${ }^{24)}$ Clinical studies have shown that disruptions in circadian rhythms may contribute to anxiety-prone traits and/or anxiety disorders. ${ }^{25)}$ Among circadian-clock genes, the SNPs of ARNTL2, DRD2, BCL2, and PAWR have been reported to be associated with $A S^{26,27)}$ In addition, RORA protein is widely expressed in brain regions including the frontal cortex, ${ }^{28,29)}$ and participates in protecting neurons and glial cells from oxidative stress-induced apoptosis. ${ }^{30)}$ Oxidative stress is one of the potential mechanisms implicated in pathophysiology of depression and anxiety disorders. In animal studies, high levels of oxidative stress induced anxiogenic behaviors ${ }^{31)}$ and vulnerability to depression. ${ }^{32)}$ These roles of RORA protein might support the biological plausibility of the association between RORA polymorphism and AS.

Results of the present study emphasize the importance of the sex in gene-environment interaction in determining AS. As in previous studies, ${ }^{9,10)} \mathrm{CM}$ was a significant environmental factor influencing AS. However, we found that $\mathrm{CM}$ interacts with RORA genotype in males but not in females. Among females, the main effects of genotype 
and maltreatment were significant. These results suggested that the level AS might be influenced differently to $\mathrm{CM}$ according to RORA genotype in males whereas it might be expected by the genotype and the experience of $\mathrm{CM}$ in females. These results are partly in line with that of a twin study, in which AS is heritable only in women and better explained by environmental factors in men. ${ }^{33)}$ It has also been reported that heritability and the impact of genetic factors might be greater among females than those among males in the studies of anxiety disorder and neuroticism. ${ }^{14,15)}$ Regarding the behavioral impact of circadian genes, a the CLOCK gene mutation has been reported to induce more pronounced behavioral changes of increased exploratory behaviors in female relative to male mice. ${ }^{34)}$ Based on the results of previous and present studies, we could hypothesize that the impact of related genes including circadian genes might be differently influenced by environmental factor on AS by sex. Further studies on the effect of sex hormones and sexual difference in epigenetic processes on brain and behaviors ${ }^{35)}$ would be required to attest our hypothesis.

There are several limitations. Sample size is small and the study design is cross-sectional. A retrospective assessment of CM may be biased by individual levels of emotionality ${ }^{36)}$ though recall bias has been reported to account for less than $1 \%$ of variance in non-clinical young adults. ${ }^{37)}$ In addition, the clinical significance of RORA rs 11071547 is yet to be determined and we did not analyze other RORA SNPs, which have been reported the associations with depression and anxiety disorders. ${ }^{4-6)}$ Recently suggested critical issues of $\mathrm{G} \times \mathrm{E}$ approach need to be duly considered. ${ }^{38)}$

In summary, we did not found the association between RORA rs11071547 and AS among healthy young adults. However, we provide the evidence of the sex-specific interaction between RORA polymorphism and CM in determining AS.

\section{Acknowledgments}

This work was supported by a grant from the Korea Health Technology R\&D project through the Korea Health Industry Development Institute (KHIDI) (grant number: HM15C1054) and the Korea Science and Engineering Foundation (KOSEF), funded by the Korean government (NRF-2015R1A2A2A01003564).

\section{REFERENCES}

1. Lavebratt C, Sjöholm LK, Partonen T, Schalling M, Forsell Y. PER2 variantion is associated with depression vulnerability. Am J Med Genet B Neuropsychiatr Genet 2010;
153B:570-581.

2. Terracciano A, Tanaka T, Sutin AR, Sanna S, Deiana B, Lai $\mathrm{S}$, et al. Genome-wide association scan of trait depression. Biol Psychiatry 2010;68:811-817.

3. Maglione JE, Nievergelt CM, Parimi N, Evans DS, AncoliIsrael S, Stone KL, et al. Associations of PER3 and RORA circadian gene polymorphisms and depressive symptoms in older adults. Am J Geriatr Psychiatry 2015;23:1075-1087.

4. Miller MW, Wolf EJ, Logue MW, Baldwin CT. The retinoidrelated orphan receptor alpha (RORA) gene and fearrelated psychopathology. J Affect Disord 2013;151:702-708.

5. Logue MW, Baldwin C, Guffanti G, Melista E, Wolf EJ, Reardon $\mathrm{AF}$, et al. A genome-wide association study of post-traumatic stress disorder identifies the retinoid-related orphan receptor alpha (RORA) gene as a significant risk locus. Mol Psychiatry 2013;18:937-942.

6. Amstadter AB, Sumner JA, Acierno R, Ruggiero KJ, Koenen KC, Kilpatrick DG, et al. Support for association of RORA variant and post traumatic stress symptoms in a population-based study of hurricane exposed adults. Mol Psychiatry 2013;18:1148-1149.

7. Stein MB, Schork NJ, Gelernter J. Gene-by-environment (serotonin transporter and childhood maltreatment) interaction for anxiety sensitivity, an intermediate phenotype for anxiety disorders. Neuropsychopharmacology 2008;33:312-319.

8. Schmidt NB, Zvolensky MJ, Maner JK. Anxiety sensitivity: prospective prediction of panic attacks and Axis I pathology. J Psychiatr Res 2006;40:691-699.

9. Stein MB, Jang KL, Livesley WJ. Heritability of anxiety sensitivity: a twin study. Am J Psychiatry 1999;156:246-251.

10. Carr CP, Martins CM, Stingel AM, Lemgruber VB, Juruena MF. The role of early life stress in adult psychiatric disorders: a systematic review according to childhood trauma subtypes. J Nerv Ment Dis 2013;201:1007-1020.

11. Klauke B, Deckert J, Reif A, Pauli P, Zwanzger P, Baumann $\mathrm{C}$, et al. Serotonin transporter gene and childhood trauma--a $G \times E$ effect on anxiety sensitivity. Depress Anxiety 2011;28:1048-1057.

12. Klauke B, Deckert J, Zwanzger P, Baumann C, Arolt V, Pauli $\mathrm{P}$, et al. Neuropeptide $S$ receptor gene (NPSR) and life events: $G \times E$ effects on anxiety sensitivity and its subdimensions. World J Biol Psychiatry 2014;15:17-25.

13. Stewart SH, Taylor S, Baker JM. Gender differences in dimensions of anxiety sensitivity. J Anxiety Disord 1997;11: 179-200.

14. Hettema JM, Prescott CA, Myers JM, Neale MC, Kendler KS. The structure of genetic and environmental risk factors for anxiety disorders in men and women. Arch Gen Psychiatry 2005;62:182-189.

15. Lake RI, Eaves LJ, Maes HH, Heath AC, Martin NG. Further evidence against the environmental transmission of individual differences in neuroticism from a collaborative study of 45,850 twins and relatives on two continents. Behav Genet 2000;30:223-233.

16. Taylor S, Cox BJ. An expanded anxiety sensitivity index: evidence for a hierarchic structure in a clinical sample. $J$ Anxiety Disord 1998;12:463-483.

17. Lim YJ, Yu BH, Kim JH. Korean Anxiety Sensitivity Index-Revised: its factor structure, reliability, and validity in clinical and nonclinical samples. Depress Anxiety 2007; 24:331-341.

18. Bernstein DP, Stein JA, Newcomb MD, Walker E, Pogge $\mathrm{D}$, Ahluvalia T, et al. Development and validation of a brief screening version of the Childhood Trauma Questionnaire. Child Abuse Negl 2003;27:169-190. 
19. Kim D, Park SC, Yang H, Oh DH. Reliability and validity of the korean version of the childhood trauma questionnaire-short form for psychiatric outpatients. Psychiatry Investig 2011;8:305-311.

20. Bernstein DP, Fink L. Childhood trauma questionnaire: a restrospective self-report: manual. Orlando:Psychological Corporation; 1998.

21. Grabe HJ, Schwahn C, Mahler J, Appel K, Schulz A, Spitzer $\mathrm{C}$, et al. Genetic epistasis between the brain-derived neurotrophic factor Val66Met polymorphism and the 5-HTT promoter polymorphism moderates the susceptibility to depressive disorders after childhood abuse. Prog Neuropsychopharmacol Biol Psychiatry 2012;36:264-270.

22. Heim C, Nater UM, Maloney E, Boneva R, Jones JF, Reeves WC. Childhood trauma and risk for chronic fatigue syndrome: association with neuroendocrine dysfunction. Arch Gen Psychiatry 2009;66:72-80.

23. Kripke DF, Kline LE, Nievergelt CM, Murray SS, Shadan $\mathrm{FF}$, Dawson A, et al. Genetic variants associated with sleep disorders. Sleep Med 2015;16:217-224.

24. Sato TK, Panda S, Miraglia LJ, Reyes TM, Rudic RD, McNamara $\mathrm{P}$, et al. A functional genomics strategy reveals Rora as a component of the mammalian circadian clock. Neuron 2004:43:527-537.

25. Coles ME, Schubert JR, Nota JA. Sleep, circadian rhythms, and anxious traits. Curr Psychiatry Rep 2015;17:73.

26. Partonen T. Clock gene variants in mood and anxiety disorders. J Neural Transm (Vienna) 2012;119:1133-1145.

27. Sipilä T, Kananen L, Greco D, Donner J, Silander K, Terwilliger JD, et al. An association analysis of circadian genes in anxiety disorders. Biol Psychiatry 2010;67:11631170 .

28. Ino H. Immunohistochemical characterization of the orphan nuclear receptor ROR alpha in the mouse nervous system. $J$ Histochem Cytochem 2004;52:311-323.

29. Nguyen A, Rauch TA, Pfeifer GP, Hu VW. Global methylation profiling of lymphoblastoid cell lines reveals epigenetic contributions to autism spectrum disorders and a novel autism candidate gene, RORA, whose protein product is reduced in autistic brain. FASEB J 2010;24:3036-3051.

30. Boukhtouche F, Vodjdani G, Jarvis CI, Bakouche J, Staels $\mathrm{B}$, Mallet $\mathrm{J}$, et al. Human retinoic acid receptor-related orphan receptor alphal overexpression protects neurones against oxidative stress-induced apoptosis. J Neurochem 2006;96:1778-1789.

31. Bouayed J, Rammal H, Soulimani R. Oxidative stress and anxiety: relationship and cellular pathways. Oxid Med Cell Longev 2009;2:63-67.

32. Bouvier E, Brouillard F, Molet J, Claverie D, Cabungcal JH, Cresto $\mathrm{N}$, et al. Nrf2-dependent persistent oxidative stress results in stress-induced vulnerability to depression. Mol Psychiatry 2016. doi: 10.1038/mp.2016.144. [Epub ahead of print $]$

33. Jang KL, Stein MB, Taylor S, Livesley WJ. Gender differences in the etiology of anxiety sensitivity: a twin study. $J$ Gend Specif Med 1999;2:39-44.

34. Easton A, Arbuzova J, Turek FW. The circadian Clock mutation increases exploratory activity and escape-seeking behavior. Genes Brain Behav 2003;2:11-19.

35. Ratnu VS, Emami MR, Bredy TW. Genetic and epigenetic factors underlying sex differences in the regulation of gene expression in the brain. J Neurosci Res 2017;95:301-310.

36. Polanczyk G, Caspi A, Williams B, Price TS, Danese A, Sugden K, et al. Protective effect of CRHRI gene variants on the development of adult depression following childhood maltreatment: replication and extension. Arch Gen Psychiatry 2009:66:978-985.

37. Fergusson DM, Horwood LJ, Boden JM. Structural equation modeling of repeated retrospective reports of childhood maltreatment. Int J Methods Psychiatr Res 2011;20:93-104.

38. Duncan LE, Keller MC. A critical review of the first 10 years of candidate gene-by-environment interaction research in psychiatry. Am J Psychiatry 2011;168:1041-1049. 